

Artigo de Revisão

\title{
Violência Doméstica entre Parceiros Íntimos: Questões Culturais e Sociais acerca dos Homens Autores de Violência
}

\author{
Marjane Bernardy Souza ${ }^{1}$, Márcio dos Santos Silva², Gabriela Silva de Abreu ${ }^{3}$
}

\begin{abstract}
Resumo: O objetivo deste estudo foi o de identificar questões sociais e culturais que expliquem os altos índices de violência contra as mulheres, provocados por seus parceiros, assim como delinear o perfil dos agressores que cometem tais atos e entender os principais fatores que motivam o surgimento da violência. Utilizou-se como método uma revisão sistemática para levantar as produções científicas, através da base de dados LILACS Literatura Latino-americana e do Caribe em Ciências da Saúde, entre os anos de 2012 e 2016, no idioma português. As buscas foram realizadas através de palavras-chave, cinco artigos corresponderam aos critérios e objetivos. Inúmeros artigos focam nas consequências e formas de enfrentamento realizados por equipes multidisciplinares ao combate à violência e/ou diminuição do sofrimento causado por esta a essas mulheres. Em contrapartida, são poucos os trabalhos publicados que procuram explicar os motivos que levam os homens a cometerem tais tipos de violência contra suas companheiras.
\end{abstract}

Palavras-chave: violência doméstica, violência contra a mulher, violência de gênero, homens agressores.

\section{Domestic Violence among Intimate Partners: Cultural and Social Issues About Men Who Commit Violence}

\begin{abstract}
This study's objective was to identify social and cultural issues that explain the high rates of violence against women caused by their partners, as well as to delineate the profile of the aggressors who execute such acts and to understand the main factors that motivate the evolution of violence. A systematic review was used as method to raise scientific production through the LILACS - Latin American and Caribbean Literature in Health Sciences database, between the years 2012 and 2016, in the Portuguese language. The searches were carried out through keywords, five articles corresponded to the criteria and objectives. Numerous articles focus on the consequences and forms of confrontation carried out by multidisciplinary teams to combat violence and / or decrease the suffering caused by it to these women. In contrast, few published works attempt to explain the reasons that conduce men to execute such violence against their female companions.
\end{abstract}

Key words: domestic violence, violence against women, gender violence, aggressive men.

\footnotetext{
${ }^{1}$ Graduação em Psicologia-Bachalerado pela Universidade do Vale do Rio dos Sinos (UNISINOS-1991) e em Psicologia-Licenciatura pela Universidade Federal do Rio Grande do Sul (UFRGS-1994), especialização em Aconselhamento das Relações Familiares pela Pontifícia Universidade Católica do Rio Grande do Sul (PUCRS-1997) e mestrado em Família e Sistemas Sociais pelo Instituto Superior Miguel Torga - Coimbra-Portugal (ISMT-2004), especialista em Psicologia no Trânsito (CFP-2010) e especialista em Psicologia Jurídica (CFP-2011). Trabalha desde 1996 como perita em Avaliação Psicológica no Departamento de Trânsito - DETRAN/RS. Coordenadora do Curso de Psicologia da Universidade Luterana do Brasil-Campus Cachoeira do Sul. Contato: marjanesouza@yahoo.com.br

${ }^{2}$ Márcio dos Santos Silva" psicologia.marcio@gmail.com

${ }^{3}$ Gabriela Silva de Abreu" <abreugabrielasilva@gmail.com>
} 


\section{Introdução}

Segundo a ONU (2016), uma das primazias para termos uma sociedade mais justa é prestar o máximo de apoio a todo tipo de combate à violência praticada contra os seres humanos. As sequelas da violência, não só físicas, mas intelectuais e psicológicas, acarretam uma série de outros problemas encontrados em larga escala dentro de consultórios médicos e de psicologia, fazendo deste um problema de saúde pública (WAISELFISZ, 2015).

Para definir a violência contra a mulher, a Organização das Nações Unidas (ONU) elaborou uma resolução que especifica esta como sendo qualquer ato baseado na diferença de gênero, que resulte em sofrimentos e danos físicos, sexuais e psicológicos à mulher, inclusive os que não chegam às vias de fato e também a coerção e privação da liberdade, sejam na vida pública ou privada (WHO, 2005).

No Brasil, existem leis que integram toda uma gama de perfis violentos, assim como o combate a estas, com ações democrático-preventivas descritas na Constituição Federal (BRASIL, 1988). A alemã Hannah Arendt, filósofa e pensadora que durante sua vida escreveu e batalhou em prol da liberdade social e dos direitos das mulheres, aborda questões culturais e fala sobre a cultura que faz diferenciações entre gêneros que coloca os homens em "vantagem" em relação às mulheres (uma sociedade machista que enxerga a mulher como um objeto, inferior e menos capaz de trabalhar ou tomar decisões). Segundo ela, isto dificultou muito a vida das mulheres quando o assunto é o sofrimento da violência, podendo esta ser presente em seus diferentes graus de classificação (física, moral, sexual ou psicológica) (ARENDT, 2008).

Em prol do combate à violência contra as mulheres, da constituição legal de direitos e na luta pela erradicação da violência gratuita e impunitiva até então bastante presente culturalmente na sociedade, foi que em agosto de 2006 ocorreu à promulgação da lei ${ }^{\circ} 11.340$ (mais conhecida como Lei Maria da Penha), após esta senhora (que deu "nome" a esta lei) sofrer e lutar por cerca de 15 anos na justiça, para que houvesse uma punição à altura para seu excompanheiro que lhe feria, lhe humilhava e por fim das contas, após dar-lhe um tiro pelas costas, à deixou sem o movimento das pernas, presa a uma cadeira de rodas (PENHA, 2009). Este combate se dá justamente, através do surgimento desta lei, pela integração do Poder judiciário, o Ministério Público e a Defensoria Pública, aumentando o rigor punitivo aos casos de violência doméstica e familiar, além de aumentar as penas aos agressores e criando medidas protetivas às agredidas (BRASIL, 2006). 
Segundo o Mapa da Violência (2015), os três principais tipos de violência sofridas pelas mulheres, no Brasil, são a violência física (58\%), a psicológica $(25 \%)$ e a sexual $(2,4 \%)$ (WAISELFISZ, 2015).

O intuito inicial da Lei Maria da Penha era erradicar a violência contra a mulher, porém estudos feitos após quase dez anos da promulgação da lei mostram que o número de casos de violência doméstica aumentou em relação aos anos anteriores à lei. A provável explicação sobre estes dados está na diminuição dos casos de omissão por parte das mulheres agredidas, que sentem-se mais seguras e encorajadas a denunciarem seus companheiros, justamente por causa das medidas protetivas existentes e da rigorosidade às punições aplicadas pelos diferentes órgãos públicos responsáveis. (AMARAL et. al., 2015; WAISELFISZ, 2015).

Campanhas publicitárias veiculadas na mídia trouxeram à tona vários casos de violência sofridos pelas mulheres, assim como as consequências possíveis àqueles que a praticam, encorajando a população a não se calar, fazendo cada um cumprir seu papel de cidadão em prol de uma sociedade mais justa, segura e saudável (ONU, 2016)

Percebe-se que inúmeros artigos no Brasil focam justamente nas consequências e formas de enfrentamento realizado por equipes multidisciplinares ao combate à violência e/ou diminuição do sofrimento causado por esta a essas mulheres. Em contrapartida, são poucos os trabalhos publicados que se atentam a entender ou explicar os motivos que levam os homens à cometerem tais tipos de violência contra suas companheiras.

O objetivo deste estudo é de identificar questões sociais e culturais que expliquem os altos índices de violência contra a mulher provocados por seus parceiros, explicando a vulnerabilidade histórica desta, assim como identificar os principais motivadores da violência e perfis dos agressores que cometem tais atos.

\section{Caracterização da violência}

O fenômeno da violência é parte constituinte da história da humanidade, com amplos e diversos impactos, estando presente no mundo todo. Entretanto, a violência sendo um problema de saúde pública e social, ameaça o desenvolvimento dos povos e afeta a qualidade de vida de todos, independente de raça, idade, condição socioeconômica ou educação (WHO, 2012). 
Ainda segundo estudo da Organização Mundial da Saúde (2012), entre as formas mais comuns de violência está aquela praticada contra a mulher, pelo parceiro íntimo, atingindo de $15 \%$ a $71 \%$ das mulheres de 10 países (incluindo o Brasil). Este tipo de violência é caracterizada por todo tipo de comportamento danoso causado por aquele com quem se mantém relação íntima, sendo este de cunho físico, moral ou sexual. Também pode ser praticado e enquadrado nestas regras, por aquele com quem se manteve algum tipo de relação (ex-companheiro).

A Organização das Nações Unidas (2012) iniciou seus esforços contra essa forma de violência na década de 50, com a criação da Comissão de Status da Mulher que formulou entre os anos de 1949 e 1962 uma série de tratados baseados em provisões da Carta das Nações Unidas - que afirma expressamente os direitos iguais entre homens e mulheres e na Declaração Universal dos Direitos Humanos - que declara que todos os direitos e liberdades humanos devem ser aplicados igualmente a homens e mulheres, sem distinção de qualquer natureza.

No Brasil, com vista ao amparo das mulheres em situação de violência, foram criadas, em 1998, as unidades de proteção asseguradas pelo Programa de Prevenção, Assistência e Combate à Violência contra a Mulher, conveniado com estados, municípios e organizações não governamentais. Mais tarde, em 2006, houve a promulgação da Lei Maria da Penha, que qualificou a violência contra a mulher como uma violação dos direitos humanos e um comportamento criminal no país (DATASENADO, 2013).

Mas o que explica o fato de os homens serem vistos como mais violentos que as mulheres?

\section{Violência de gênero: motivadores epistemológicos e sociais da "cultura do machismo"}

O modelo social dominador e de supremacia a qual todos estamos sujeitos revela e explica em grande parte os motivos pelos quais os homens possuem um comportamento violento e se submetem com maior frequência do que as mulheres a situações de risco. Estudos sobre a relação "homem-violência" apresentam explicações vinculadas à socialização dos homens, calcado num modelo hegemônico de masculinidade instituidor de papéis de soberania, valentia, honra, dominação, força e invulnerabilidade (CONNEL e MESSERSCHMIDT, 2013). 
Este modelo torna a violência uma prática natural e até esperada por parte de uma classe que necessita se mostrar mais forte que o sexo oposto e até entre seus iguais. Portanto, as condutas autoritárias e a adoção às praticas de risco servem como um instrumento de afirmação do "ser homem" (ARENDT, 2008).

O mapa da violência de 2015 informa que a taxa de mortalidade masculina provocada pelo fator "acidentes" e "violência" (chamadas nos relatórios governamentais de causas externas) é de $92,5 \%$ de todas as mortes ocorridas no Brasil, deixando assim o sexo feminino com apenas 7,5\% deste índice (WAISELFISZ, 2015). Estes números mostram que a relação de mortes entre homens e mulheres encontra-se numa taxa de 16:1. A expectativa de vida dos homens atualmente, no Brasil, é de 71,6 anos, enquanto que para as mulheres essa expectativa é de 78,8 anos. Essa diferença está diretamente ligada à inserção do homem em comportamentos violentos. Isso mostra que a violência, assim como outros problemas de saúde, não é igualmente distribuída entre os sexos ou grupos etários (IBGE, 2015).

Não é novidade comentar que vive-se numa cultura machista e misógina. Desde "brincadeiras" infantis a propagandas veiculadas na mídia mostram diariamente que as mulheres ainda encontram-se numa posição "inferior" aos homens. Desde comentários corriqueiros como "mulher no volante, perigo constante" a pessoas que não confiam em profissionais (por exemplo, médicas ou policiais) pelo simples fato de serem mulheres, se faz salientar que o machismo está intrincado muito fortemente na cultura brasileira. Casos de estupro onde as mulheres são culpabilizadas pela sociedade por causa de sua vestimenta ou seu modo de agir, também mostram que a sociedade brasileira como um todo ainda está muito atrasada quando o assunto é a liberdade e igualdade de gênero (CASTRO, 2015).

\section{A vulnerabilidade da mulher ao longo da história}

Para entender a prática da violência de gênero (masculino sobre o feminino), podemos analisar antigos escritos dos primórdios da cultura ocidental, onde eram tratados abertamente e sem pudor a desigualdade e inferioridade do sexo feminino perante a sociedade. (CASTRO, 2015).

Dos primórdios da escrita, a mitologia grega conta que Pandora, por curiosidade própria de seu sexo, havia aberto a caixa onde estavam guardados todos os males do mundo, 
responsabilizando as mulheres por terem desencadeado todo o tipo de desgraças. Nesta mesma sociedade, as mulheres não tinham direitos políticos ou jurídicos, eram proibidas de aparecer em público sozinhas, não recebiam educação formal, e eram confinadas em suas próprias casas em aposentos particulares, enquanto aos homens era admitido estes e muitos outros direitos (PINAFI, 2012).

Num estudo histórico realizado por esta mesma autora, embasado na filosofia e na religião, por diversas vezes é citada a inferioridade do ser do sexo feminino, que na cultura romana não era vista como cidadã, não podendo assim exercer cargos públicos. Sob um prisma religioso, a mulher, no paraíso, foi retratada como a pecadora e responsável pela expulsão da raça humana do lugar, atribuindo também a uma possível incapacidade de mentalização por seus atos.

O filósofo grego Aristóteles escreveu em "A Política" que a mulher era inferior e absolutamente submissa ao marido, não tendo ela capacidade de decisão ou de opinião sobre os atos deste, nomeando inclusive esta subserviência de "despotismo marital" (ARISTÓTELES, 2009).

Percebe-se com estes escritos ao longo dos séculos, a cultura machista que era imposta e aceita pela sociedade como algo natural e imutável, sem trazer questionamentos, pois através desta visão naturalista, a ordem patriarcal imperava, inclusive na sociedade brasileira, a qual atribuiu aos homens o direito de controlar e dominar suas mulheres, podendo em certos casos, fazer uso da violência (PINAFI, 2012).

A revolução francesa, em 1789 é vista como um marco na história da mudança da visão feminina perante a sociedade. As mulheres participaram ativamente do processo revolucionário ao lado dos homens por acreditarem que os ideais de igualdade, fraternidade e liberdade seriam estendidos a sua categoria. Ao constatar que as conquistas políticas não se estenderiam ao seu sexo, algumas mulheres se organizaram para reivindicar seus ideais não contemplados (BLUCHE et al., 2009).

Passado mais um século, durante a revolução industrial e a consolidação capitalista, foram vistas grandes mudanças na sociedade como um todo. A mão-de-obra feminina foi utilizada nas fábricas, retirando estas mulheres do âmbito privado e as colocando-as na esfera pública. Neste processo, elas têm a oportunidade de questionar sobre a subjetiva superioridade masculina, formando assim o chamado "movimento feminista" e abrindo as portas à analise do binômio dominação-exploração construído ao longo dos tempos (PINAFI, 2012). 
Quase dois séculos após a revolução francesa, em 1979, a Assembleia Geral das Nações Unidas realiza uma importante convenção para tratar do assunto da discriminação das mulheres, dando origem à Lei Internacional dos Direitos da Mulher e ao CEDAW, comitê que trata da Eliminação De Todas As Formas De Discriminação Contra A Mulher que visou à promoção dos direitos da mulher na busca da igualdade de gênero, bem como a repressão de quaisquer discriminações. Ao aceitar a Convenção, os Estados comprometeram-se a proceder com uma série de medidas para acabar com a discriminação contra as mulheres em todas as formas, iniciando oficial e juridicamente a luta pela igualdade de direitos entre homens e mulheres nas diferentes esferas da sociedade (ONU, 1979; BRASIL, 1984).

Nesta onda de reconhecimento dos direitos femininos e na criação de mecanismos legais com a finalidade de coibir a violência contra as mulheres, finalmente em 2006, no Brasil, foi sancionada a Lei 11.340 (conhecida como "Lei Maria da Penha", citada anteriormente), visando incrementar e destacar o rigor das punições para crimes contra a mulher. E mais recentemente ainda, em março de 2015 foi sancionada a Lei 13.104/2015, chamada de "Lei do Feminicídio", classificando-o como crime hediondo e com agravantes quando acontece em situações específicas de vulnerabilidade (gravidez, menor de idade, na presença de filhos, etc.) (WAISELFISZ, 2015).

\section{Caracterização e perfil do agressor}

Segundo o autor Jorge Corsi (2005), psicólogo argentino especialista em violência familiar e de gênero, as principais hipóteses para explicar à violência dos homens contra as mulheres são: a) Hipótese cultural: a violência contra as mulheres está ancorada nos valores patriarcais que favorecem e justificam a manutenção de uma ordem social e familiar violenta; b) Hipótese estrutural: as raízes da violência residem nas desigualdades sociais e na falta de oportunidades que desencadeiam tensões e agressividade nos indivíduos; c) Hipótese psicopatológica: o comportamento violento é fruto das disfunções da personalidade daquele que a exerce, logo estaria relacionado à impulsividade, à psicopatia ou ao uso abusivo de álcool e/ou droga; d) Hipótese interacionista: a causa da violência estaria nos estilos das relações estabelecidas entre os cônjuges, seja no aspecto verbal, emocional ou comportamental; e) Perspectiva jurídica que, apesar de não se constituir como uma explicação da violência, pontua 
o aspecto normativo e punitivo daquele que a pratica, abordando o grau da detenção, denúncia e condenação penal dos maltratadores familiares (LOPES, 2013).

Analisando tais fatores, pode-se inferir que a violência doméstica contra a mulher não pode ser pautada por classes sociais menos favorecidas ou por pessoas com menor grau de instrução escolar, apesar dos índices oficiais mostrarem uma incidência muito maior de violência doméstica ocorrendo em famílias de classes menos abastadas (WAISELFISZ, 2015). Várias hipóteses propostas por Corsi (2005) explicam o motivo de muitas vezes famílias classificadas como de classe alta (economicamente), terem esse problema dentro de suas casas, porém justamente por uma questão de proteção e status social, não se divulgam tais notícias. Somente a hipótese estrutural tenciona os motivadores da violência às desigualdades sociais presentes em nosso país. Por causa disso, muitas vezes o levantamento dos dados da violência são mascarados por este modelo familiar que "resolve" não levar adiante à esfera jurídica tais situações (LOPES, 2013).

Segundo o mapa da violência contra a mulher publicado no ano de 2015, 67,2\% de todas as agressões cometidas no Brasil são de violência doméstica, praticada contra as mulheres por parentes imediatos, parceiros ou ex-parceiros. No Estado do RS este índice se mantém praticamente o mesmo. (MAPA DA VIOLÊNCIA - HOMICÍDIOS, 2015)

Dados publicados na última edição do relatório Lilás (documento permanente do Parlamento gaúcho que tem como objetivo discutir sobre as políticas públicas de gênero e que é organizado pela Frente Parlamentar dos Homens pelo Fim da Violência Contra a Mulher), a cada vinte minutos uma mulher sofre algum tipo de agressão física com lesão corporal no Rio Grande do Sul. Este mesmo relatório trás a estatística de que 74,4\% das agressões que resultam em morte de mulheres acontecem dentro de suas próprias casas (RELATÓRIO LILÁS, 2015).

Em pesquisa realizada no ano de 2015 pelo órgão público DataSenado, 100\% das mulheres dizem conhecer a Lei Maria da Penha. Nesta mesma pesquisa, em levantamento feito à respeito da ocorrência de agressões, $20 \%$ das mulheres dizem já ter sofrido algum tipo de violência, indo ao encontro das estatísticas nacionais. Destas, dois terços relataram sofrer agressões físicas e metade de todas as mulheres relatam sofrer agressões psicológicas (DATASENADO, 2015).

O desrespeito dos parceiros íntimos percebido pelas mulheres aumentou em relação a pesquisas nacionais realizadas em anos anteriores. Cerca de $43 \%$ das mulheres não se sentem 
completamente respeitadas por seus parceiros, sendo que na pesquisa anterior a esta, realizada em 2013, este índice era de 35\% (DATASENADO, 2015).

Como referido anteriormente e comprovado em todas as pesquisas dos órgãos responsáveis, na extrema maioria dos casos (que fica na média de 70\%), as mulheres sofrem agressões dos maridos, companheiros (com quem mantém moradia fixa, porém sem ligações legais), namorados e ex, sendo responsáveis por este comportamento principalmente as questões culturais de uma vida conjugal deficiente, com o início do relacionamento levado de forma positiva e respeitosa por parte de seus companheiros, mas que com o passar do tempo transforma-se numa relação de controle e reprovação, iniciando o ciclo da violência até chegar na agressão. Nestas mesmas pesquisas, ainda falando sobre o cônjuge, estipula-se que a idade em que mais se pratica a violência contra a mulher está entre os 18 (até 29 anos - classificados como jovem, responsável por cerca de 30\% das agressões) e 59 anos (a partir dos 30 classificados como adultos, responsáveis por cerca de 34\% das agressões) (DATASENADO; RELATÓRIO LILÁS; MAPA DA VIOLÊNCIA; ACOSTA et. al., 2015).

\section{Principais Motivadores}

Pode-se analisar os principais motivadores da violência sob um aspecto patriarcal, dominador e controlador dos homens sobre as mulheres (ACOSTA, 2015), já apresentados e discutidos anteriormente neste trabalho.

Em pesquisas realizadas por diversas agências governamentais responsáveis por identificar e mensurar os números da violência no Brasil (MAPA DA VIOLENCIA; DATASENADO, 2015), enxerga-se claramente que o principal motivo alegado pelos agressores e agredidas é o ciúme, também encontrado na literatura como "comportamento emocional ciumento", seguido pelo uso abusivo de drogas e/ou álcool (LACERDA e COSTA, 2013), sendo o primeiro responsável por $21 \%$ do total de agressões e o segundo por $18 \%$ delas (DATASENADO, 2015).

O ciúme visto sob um aspecto pontual é mensurado em diversas pesquisas, levando em conta a resposta dos participantes como positivo (aquele que acontece diante de um fato realmente existente) ou negativo/patológico (quando ocorrido em momentos que o parceiro 
imagina uma situação ou cria uma história para reprimir a parceira) (LACERDA e COSTA, 2013; MALLMANN, 2015).

Já tratando-se sobre o uso de drogas e/ou álcool, Separavich e Canesqui (2013) chegam à conclusão de que, sob efeito de algum tipo de entorpecente, o homem permite aflorar os descontentamentos gerais na vida pessoal ou social, somado ao controle que este necessita ter em sua relação conjugal, levando este a um comportamento violento e desmedido para com sua parceira.

\section{Processos Metodológicos}

Esta pesquisa caracteriza-se como qualitativa, do tipo exploratório, utilizando como método a revisão sistemática dos dados para levantar produções científicas a respeito do tema proposto através da base de dados LILACS - Sistema Latino-Americano e do Caribe de Informação em Ciências da Saúde. Uma revisão sistemática consiste em uma forma de pesquisa que utiliza, como fonte de dados, a literatura sobre determinado tema e disponibiliza um resumo das evidências relacionadas a uma estratégia de intervenção específica, mediante a aplicação de métodos explícitos e sistematizados de busca, a apreciação crítica e a síntese da informação selecionada (GOMES e CAMINHA, 2014).

\section{Estratégias de Busca}

Para tal pesquisa, utilizou-se a busca dos artigos através de palavras-chave: violência doméstica, violência contra a mulher, violência de gênero, homens agressores, com o cruzamento destas e a interdependência entre as mesmas. Estas palavras-chave foram filtradas no campo "assunto principal" pelos descritores "violência contra a mulher", "violência doméstica", "mulheres agredidas" e foram limitadas pelo período de publicação de janeiro de 2012 a agosto de 2016, pelo idioma português, (BR) pelo tipo de documento artigo e que continham texto completo disponível. 


\section{Coleta de Dados}

Neste trabalho incluiu-se os artigos que os resumos foram submetidos aos seguintes critérios: 1) praticada pelo cônjuge e que analisam o 2) perfil dos agressores, excluindo-se os artigos que tratam a violência contra a mulher de forma generalizada. De grande importância também, incluiu-se os artigos que abordam o tema dos 3) motivadores da violência, e finalizando, foram selecionados artigos que tratam sobre a 4) vulnerabilidade histórica da mulher diante do comportamento violento do cônjuge. Os critérios [ 1) e 2) ] foram considerados obrigatórios para a inclusão dos artigos, assim sendo, todos os artigos selecionados acompanham pelo menos estes critérios.

Na busca à base de dados LILACS foram encontrados 98 artigos, dentre os quais foram analisados seus resumos. Nesta triagem inicial, excluíram-se os artigos que tratavam de diferentes tipos de violência e que abordavam diferentes questões (total de 87 artigos), não se enquadrando aos parâmetros propostos. Após mais esta etapa, realizou-se a leitura na íntegra de 11 artigos, encaixando-se a eles os critérios de inclusão com maior atenção e rigorosidade. Nesta etapa, selecionou-se cinco artigos que se adequaram ao tema proposto e cumpriram os critérios do estudo.

\section{Análise Dos Dados}

Para a construção deste estudo, foram analisados os dados dos artigos selecionados conforme descrito na coleta de dados. Após esta análise, realizou-se a leitura na íntegra destes artigos, sistematizando este processo através do agrupamento destes conforme os temas propostos nos objetivos deste estudo. Foram discorridos cada um, descrevendo o que cada autor contribuiu em relação aos objetivos principais deste estudo

\section{Resultados e Discussão}

A pesquisa realizada no banco de dados LILACS resultou em cinco artigos considerados pertinentes ao estudo. Todos eles abordam o tema da violência que é praticada contra as 
mulheres pelo cônjuge ou ex, bem como, a discussão sobre o perfil deste agressor. Foram publicados entre os anos de 2012 e 2014, sendo todos eles estudos qualitativos.

O estudo de OLIVEIRA E.R. (2012) aborda a questão da vulnerabilidade histórica da mulher, fazendo um passeio sobre importantes acontecimentos que culminaram na conquista de direitos e a luta pela igualdade das mulheres.

O estudo de ALVES, R.A. et al. (2012) destaca o homem como vítima da sociedade à qual precisa este mostrar poder e domínio para sentir-se sujeito, delineando um perfil destes homens agressores. Já OLIVEIRA E.C. (2014) pauta seu artigo num discurso sobre gênero e violência, levando em consideração a opinião da sociedade sobre o assunto.

Finalmente, DOURADO S. \& NORONHA C. (2014) e LACERDA L. \& COSTA N.(2013) refletem, além da questão social que naturaliza a violência praticada contra a mulher, os principais motivadores que levam à maioria das agressões conjugais.

Num primeiro momento, nesta discussão de resultados, será abordado o tema da vulnerabilidade da mulher, imprimindo neste assunto os artigos pertinentes a ele. Em um segundo momento, será debatido o perfil do agressor, mostrando o que cada autor, entre os artigos selecionados, apresentam conforme seus estudos.

Finalizando, será mostrado nesta discussão a teorização dos dois principais motivadores, alegados pelos autores e pelas vítimas, das agressões contra as mulheres.

\section{Mulheres vulneráveis}

Quando se trata de violência, o estudo dos autores ALVES, R.A. et al. (2012) aborda o tema como uma forma de dominação que perpassa as relações humanas. Apesar de homens e mulheres estarem sujeitos ao envolvimento com a violência, é o primeiro gênero que está intrinsecamente ligado a esta, explicado por teorias biológicas e levado em consideração os números da violência de relatórios governamentais. Estes autores explicam o problema pelo viés da vulnerabilidade a que os homens estão submetidos, agravada pela socialização que os condiciona, quase que obrigatoriamente, a uma posição de dominadores, aprisionando-os num modelo autodestrutivo.

Tratando da lógica da dominação, da mesma forma que existem os dominadores, estes autores inferem que existam os que se subjugam a este modelo, e é justamente essa dinâmica 
que faz com que conflitos entre estes sejam tão comuns, provocando relações desiguais que geram a necessidade de afirmação sobre o outro, como referência compensadora à valentia na qual precisam estar submetidos. Ou seja, aquele homem que por necessidade precisa submeterse às ordens de outro, em algum momento necessita também dar ordens, gerando assim um círculo perpétuo de dominação/subjugação (OLIVEIRA E.R. (2012).

O papel da mulher, nesse aspecto, está vinculado à menor força física e liberdade social que esta subjetivamente possui, relacionado às construções de gênero pautadas num modelo dominador e pouco altruísta da maioria dos homens, criando cenários de violência que se configuram como "relações de força expressas enquanto relações de dominação", presente quando o cônjuge se vê numa posição de possível inferioridade diante da companheira (ALVES, R.A. et al., 2012).

Para a autora OLIVEIRA E.R. (2012), o modelo de subjugação do sexo feminino esta pautado sobre uma temática social e econômica. Ela concorda com ALVES, R.A. et al. (2012) citando o modelo dominador que a sociedade ao longo dos séculos construiu, porém estende a abordagem para uma temática vitimizadora da mulher, que sempre foi vista por todos como não detentora dos mesmos direitos reservados aos homens. Sobre a questão econômica, a autora explica que o capitalismo e o surgimento da propriedade privada contribuíram com a cultura discriminatória e opressora para com a mulher, onde o valor desta era visto apenas diante da função reprodutiva e posteriormente cuidadora dos filhos e do lar.

Historicamente falando, OLIVEIRA E.R. (2012) cita autores como Gustave Lebon, um dos fundadores da psicologia social que afirmou certa vez que "uma mulher inteligente era tão raro quanto um gorila de duas cabeças" ou Charles Darwin que reconhecia algumas qualidades das mulheres, mas mesmo assim as definia como sendo de "raças inferiores". Nesta mesma temática, explica-se a vulnerabilidade feminina sob o aspecto cultural, visto que (concordando mais uma vez com ALVES, R.A. et. al., 2012) as mulheres na sua constituição física, geralmente possuem menor força para o trabalho do que os homens, não sendo suficientemente útil para o trabalho no campo, local do qual dependia o sustento da família, e isto era tomado como algo natural por toda a sociedade.

Falando sobre a vulnerabilidade feminina e relacionando esta com a questão da violência, os autores DOURADO S. \& NORONHA C. (2014) e OLIVEIRA E.R. (2012) utilizam o termo "violência de gênero", com o objetivo de destituir o mito que marcava a diferença sobre as funções biológicas humanas. Este termo, segundo os autores, desconstrói as 
argumentações de subordinação feminina centradas exclusivamente em fatores orgânicos, fazendo com que se discuta o problema que gera a violência doméstica contra a mulher, como uma questão cultural e social. Sob esse aspecto, esta nova terminologia serviu para que se colocasse em pauta justamente as diferenças entre os gêneros, uma vez que, excluindo a gestação e a lactação, não existe nenhuma outra característica biológica que se permita diferenciar o masculino do feminino. O agravante percebido ao longo da história, segundo OLIVEIRA E. C. (2014) foi justamente a aceitação cega da sociedade como um todo, a subordinação das mulheres por questões de necessidade, visto que a elas não era permitido terem empregos formais ou direitos de instância econômica ou social e o aproveitamento abusivo dos homens diante dessa situação.

A história começou efetivamente a ser modificada, segundo a autora OLIVEIRA E.R. (2012), com alguns marcos históricos, como a revolução norte-americana, quando em 1776 John Stuart Mill reivindicou para as mulheres as promessas da Declaração de Independência, seguida pela a revolução francesa, acontecimento que gerou a "Declaração dos Direitos da Mulher e da Cidadã”, redigida por Olímpia de Georges em 1791 (documento este que foi inspirado na "Declaração dos Direitos dos Homens", existente na época. Também pode ser citada a autora Mary Wollstonecraft, escritora e filósofa inglesa que durante sua vida batalhou e defendeu a igualdade de direitos das mulheres, que escreveu, em 1792, “A reivindicação dos direitos da mulher", livro este discutido nos parlamentos de vários países europeus da época. Estes documentos, portanto, são vistos como as bases conceituais e teóricas capazes de proporcionar os debates e reflexões que fomentaram as discussões pela igualdade entre os sexos. Durante os séculos XIX e XX autores, filósofos, pensadores continuaram a discutir e repensar o papel da mulher na sociedade, tanto que na revolução industrial a mão de obra feminina começou a ser utilizada em larga escala, dando a estas também o direito de serem ouvidas perante a sociedade, mesmo sabendo que a opinião dos homens ainda seria mais forte que a delas.

Para a autora OLIVEIRA E. C. (2014), o importante ao longo da história foi justamente a desconstrução das estruturas de classe, onde as diferenças biológicas, de gênero e sexualidade passaram a não ser tratadas como variáveis independentes, visto que a opressão que uma sofre está inscrita na outra. 


\section{Cônjuges agressores}

Como visto anteriormente, a maioria das agressões sofridas pelas mulheres acontece por seus cônjuges ou por pessoas com quem estas mulheres já tiveram algum tipo de relação íntima (DATASENADO, 2015).

Segundo os autores ALVES, R.A. et al. (2012), este processo se dá justamente pela posição em que os homens enxergam-se diante das mulheres. $O$ conceito social atual praticamente os obriga a serem os "provedores" da família, trabalhando para o sustento desta e tomando as mais importantes decisões na sociedade, sendo este o "chefe da casa". Este movimento provoca uma pressão inconsciente, que somado às questões culturais de centralização de poder, aprendidos desde a infância, subjetivamente também dá o direito a estes sobre as atitudes e o corpo da mulher, provocando conflitos entre o casal e gerando a violência.

A autora OLIVEIRA E.R. (2012) admite o conceito machista e patriarcal instituído ainda na sociedade atual e acrescenta que a violência ritualizada e secularmente praticada se origina de conflitos interpessoais e se desenvolve no espaço privado, fazendo com que os envolvidos, muitas vezes enxergando tais manifestações como comuns de relações íntimas e acontecidas ao redor de uma entidade relativamente inviolável (a família), considerem tais delitos como meros problemas conjugais.

Os autores DOURADO S. \& NORONHA C. (2014) abordam a temática da violência conjugal sob um aspecto binomial e percebem a mulher como "protagonista e vítima" numa relação deficiente onde a violência se faz presente. Protagonista porque ela é parte constituinte da relação e tem seu papel estabelecido na construção desta. E vítima, pois esta interação se dá num cenário historicamente forjado em uma ideologia machista, onde as mulheres são as que, majoritariamente, sofrem abusos físicos e psicológicos devido ao alto grau de responsabilidade delegado aos homens, já de natureza violenta. Estes, não sabendo lidar de forma positiva com os problemas, acabam "descontando" as agruras da vida em quem está mais próximo, ou seja, a companheira. 


\section{Acerca dos motivadores}

As autoras LACERDA L. \& COSTA N. (2013) tratam diretamente sobre os comportamentos que dão origem à violência praticada contra a mulher, especificamente o ciúme. Sendo este também o motivo de maior incidência alegado em pesquisa nacional, divulgada no ano de 2015, pela agência DataSenado (DATASENADO, 2015).

Contudo, segundo estas autoras, mesmo que o ciúme seja percebido como uma causa da violência, é possível tratá-lo de outro modo, visto sob um enfoque comportamental. Inclusive a proposta do artigo analisado é de fazer esta desconstrução e enxergar o real culpado de uma relação deficitária, utilizando assim não exatamente o termo "ciúmes", mas sim a expressão "comportamento emocional ciumento", sendo este alimentado por toda a cadeia comportamental já discutida anteriormente, onde a mulher é vista como sexo frágil e não detentora de direitos sobre seu próprio corpo. A maior causa deste comportamento se dá quando o companheiro imagina que a mulher possa traí-lo, sentindo-se dessa forma, com seus direitos de "macho dominador", violado, aglutinando as informações com os estudos dos autores ALVES, R.A. et al. (2012), DOURADO S. \& NORONHA C. (2014), OLIVEIRA E. C. (2014) e OLIVEIRA E.R. (2012) (LACERDA L. \& COSTA N. (2013).

O outro principal motivador destacado na pesquisa do órgão DataSenado (2015) e discutido pelos autores ALVES, R.A. et al. (2012) é o uso de álcool e/ou drogas. Sendo o uso do álcool, pelo menos, largamente difundido na sociedade e incentivado na cultura do nosso país, principalmente para os homens, os autores enxergam que dessa forma eles sentem-se mais poderosos, com uma sensação de invulnerabilidade, de aumento de força. Somando esta reação dos entorpecentes às questões que ferem ou ameaçam (real ou subjetivamente) a honra e os tradicionais atributos masculinos impostos pela sociedade, a prática da violência assume um papel punitivo e é a real expressão do homem afirmar seu domínio sobre a mulher ou demarcar sua propriedade diante das outras pessoas.

\section{Conclusão}

Nos últimos anos, a preocupação e luta pelos direitos fundamentais das mulheres tem se tornado de grande recorrência, fazendo justamente com que profissionais de diversas áreas 
interajam entre si agregando conhecimentos e batalhando para que estes direitos sejam cumpridos por toda a sociedade.

A violência contra a mulher é um assunto que cada vez mais entra em pauta de discussões sociais e políticas no nosso país, trazendo preocupação em diversas esferas e buscando estratégias de enfrentamento contra ela. Neste sentido, o presente estudo procurou fazer uma revisão sistemática acerca das questões culturais que historicamente vulnerabilizam as mulheres, assim como o delineamento do principal perfil dos agressores e seus motivadores mais contundentes.

Entender os motivos pelos quais os homens são mais violentos que as mulheres tornase, assim, de suma importância, visto que os trabalhos realizados com os agressores poderiam estar auxiliando no caminho da erradicação do problema de forma mais precisa e eficaz.

Levando em consideração os aspectos mencionados, entende-se que ainda é pequena a produção de estudos acerca da visão masculina do problema da violência doméstica.

Desta forma, percebe-se a necessidade da realização de novos e atuais estudos sobre o tema, abrindo dessa forma, um caminho para futuras pesquisas que abordem essas questões.

Acredito que este tema possa ser discutido mais amplamente no meio acadêmico, visto se tratar de um assunto tão preocupante e presente na nossa sociedade, através de grupos de estudos e seminários que abranjam não apenas o corpo docente e discente das universidades, mas a comunidade como um todo, realizando consequentemente uma verdadeira transformação e gerando o conhecimento necessário, em prol de um corpo social mais justo e digno para todos.

\section{Referências}

ACOSTA, Daniele Ferreira; GOMES, Vera Lúcia de Oliveira; FONSECA, Adriana Dora da; GOMES, Giovana Calcagno. Violência Contra A Mulher Por Parceiro Íntimo: (In)Visibilidade Do Problema. Revista Contexto Enfermagem, Florianópolis, Jan-Mar; 24(1), 2015.

ALVES, Rejane Aparecida et al. Men, victims and perpetrators of violence: the corrosion of public space and the loss of the human condition. Interface - Comunicação, Saúde e Educação, out./dez. - 2012.

ARENDT, Hannah. A condição humana. Trad. Roberto Raposo. $10^{\text {a }}$ ed. Rio de Janeiro: Forense Universitária, 2008.

ARISTÓTELES. A Política. Editora EDIPRO - São Paulo, 2009. ISBN: 8572836128 
BLUCHE, Fréderic; RIALS, Stéphane; TULARD, Jean. Revolução Francesa. L\&PM Editores, Ed.1, 2009. ISBN: 8525418676

BRASIL. Constituição (1988). Constituição da República Federativa do Brasil. Brasília, DF: Senado Federal: Centro Gráfico, 1988. 292 p.

Convenção sobre a Eliminação de Todas as Formas de Discriminação contra a Mulher (CEDAW, 1979) - promulgada pelo Decreto no 89.460, de 20/03/1984. Coleção de Leis do Brasil - 1984, Página 323 Vol. 2. Disponível em: http://www2.camara.leg.br/legin/fed/decret/1980-1987/decreto-89460-20-marco-1984439601-publicacaooriginal-1-pe.html. Acesso em 09 de outubro de 2016.

Lei n. 11.340, de 7 de agosto de 2006: cria mecanismos para coibir a violência doméstica e familiar contra a mulher, nos termos do $\S 8^{\circ}$ do art. 226 da Constituição Federal. Brasília (DF); 2006. Disponível em: https://www.planalto.gov.br/ccivil_03/_Ato20042006/2006/Lei/L11340.htm. Acesso em: 12 de set. de 2016.

CAMPOS, Amini Haddad. Violência institucional de gênero e a novel ordem normativa: inovações processuais na Lei Maria da Penha. In: LIMA, Fausto Rodrigues de; SANTOS, Claudiene. (Coord.). Violência doméstica: vulnerabilidades e desafios na intervenção criminal e multidisciplinar. Rio de Janeiro: Lumen Juris, 2010.

CASTRO, Roney Polato de. "O homem pode tudo”... “A mulher é um sexo inferior!"...: Discutindo Sexismo, Machismo E Violência Contra As Mulheres Na Formação em Pedagogia. Simpósio Internacional de Educação Sexual: Feminismos, identidades de gênero e políticas públicas. Paraná, 2015.

CONNELL Robert.; MESSERSCHMIDT James. Masculinidade hegemônica: repensando o conceito. Revista Estudos Feministas, Florianópolis, Jan.-Abr, 2013.

CORSI, Jorge. Modelos de intervención con hombres que ejercen violencia en la pareja. Feminismo/s, Buenos Aires, 2005.

DATASENADO. Violência Doméstica e Familiar contra a Mulher. Secretaria de Transparência, 2013. Disponível em: $<$ http://www.senado.gov.br/senado/datasenado/pdf/datasenado/DataSenado-PesquisaViolencia_Domestica_contra_a_Mulher_2013.pdf >. Acesso em: 20 de outubro de 2016.

DOURADO Suzana de Magalhães; NORONHA Ceci Vilar. A face marcada: as múltiplas implicações da vitimização feminina nas relações amorosas. Physis Revista de Saúde Coletiva, Rio de Janeiro, 24 [ 2 ]: 623-643, 2014.

GIL, Antônio Carlos. Como elaborar projetos de pesquisa. $5^{\mathrm{a}}$.ed. São Paulo: Editora Atlas, 2010 .

GOMES, Isabelle; CAMINHA, Iraquitan. Guia para estudos de revisão sistemática: uma opção metodológica para as Ciências do Movimento Humano. Revista Movimento - Porto 
Alegre,

$\mathrm{jan} / \mathrm{mar}$,

2014.

Disponível

em: http://www.seer.ufrgs.br/Movimento/article/viewFile/41542/28358. Acesso em: 01 de novembro de 2016.

IBGE - Pesquisa nacional de saúde. Brasil, grandes regiões e unidades da federação. - Rio de Janeiro : IBGE, 2011.

-Tábua completa de mortalidade para o Brasil - 2014. Breve análise da evolução da mortalidade no Brasil. - Rio de Janeiro: IBGE, 2015.

LACERDA, Larissa; COSTA, Nazaré. Relação entre comportamentos emocionais ciumentos e a violência contra a mulher. Revista Brasileira de Terapia Comportamental e Cognitiva, Vol. $\mathrm{XV}, \mathrm{n}^{\circ}$ 3, 2013.

LOPES, Paulo Victor (org.) Atendimento a homens autores de violência doméstica: desafios à política pública. Rio de Janeiro - Iser, 2013, ISBN: 9788576190165

MALLMANN, Cléo José. Ciúmes: do normal ao patológico. Estud. psicanal. № 43 - Belo Horizonte, jul., 2015.

MOURA, Erly. Perfil da situação de saúde do homem no Brasil. Rio de Janeiro: Fundação Oswaldo Cruz - Instituto Fernandes Figueira, 2012.

OLIVEIRA, Érika Cecília. "Eu também sei atirar"!: Reflexões sobre a Violência contra as Mulheres e Metodologias Estético Políticas. Revista PSICOLOGIA: CIÊNCIA E PROFISSÃO, 34(3), 2014.

OLIVEIRA, Elisa Rezende. Violência doméstica e familiar contra a mulher - um cenário de subjugação do gênero feminino. Revista do Laboratório de Estudos da Violência da UNESP/Marília - Revista LEVS/UNESP - Marília - Edição 9 - Maio, 2012.

ONU - ORGANIZAÇÃO DAS NAÇÕES UNIDAS. Server Brasil. Disponível em https://nacoesunidas.org/brasil-a-cada-6-horas-uma-mulher-e-assassinada-por-um-agressorconhecido-alerta-onu-mulheres/, 2016. Acesso em: 12 de set. de 2016.

- United Nations - UN. Convention on the Elimination of All Forms of Discrimination against Women. New York, 18 December, 1979. Disponível em: http://www.undocuments.net/cedaw.htm. Acesso em: 09 de outubro de 2016.

PENHA, Maria da. Sobrevivi... Posso Contar - Armazém da Cultura, ISBN: 9788584920099 - São Paulo, 2009.

PINAFI, Tânia. Violência contra a mulher: políticas públicas e medidas protetivas na contemporaneidade. Revista Histórica do Estado de São Paulo, 2012. Disponível em: http://www.historica.arquivoestado.sp.gov.br/materias/anteriores/edicao21/materia03/texto03. pdf. Acesso em: 09 de outubro de 2016. 
ROCHA, Carmen Lúcia. O Direito a uma vida sem violência. In: LIMA, Fausto Rodrigues de; SANTOS, Claudiene (Coord.). Violência doméstica: vulnerabilidades e desafios na intervenção criminal e multidisciplinar. Rio de Janeiro: Lumen Juris, 2010.

SAMPAIO, Rosana; MANCINI, Marisa Cotta. Estudos de revisão sistemática: um guia para sintese criteriosa da evidência científica. Rev. bras. fisioter. 2007.

SEPARAVICH, Marco Antônio; CANESQUI, Ana Maria. Saúde do homem e masculinidades na Política Nacional de Atenção Integral à Saúde do Homem: uma revisão bibliográfica. Saude soc. vol.22 no.2 São Paulo Abr./Jun., 2013.

WAISELFISZ, Júlio Jacobo. Mapa da violência 2015. Homicídio de mulheres no Brasil. Instituto Sangari. Brasília - DF. 2015. Disponível em:

http://www.mapadaviolencia.org.br/pdf2015/MapaViolencia_2015_mulheres.pdf . Acesso em: 29 de setembro de 2016.

Mapa da Violência 2015. Mortes Matadas por Armas de Fogo. Instituto Sangari.

Brasília - DF. 2015, 2015. Disponível em:

http://www.mapadaviolencia.org.br/pdf2015/mapaViolencia2015.pdf . Acesso em: 29 de setembro de 2016.

WORLD HEALTH ORGANIZATION (2005). Multi-country study on women's health and domestic violence against women. Summary report of initial results on prevalence, health outcomes and women's responses. Disponível em: http://www.who.int/gender/violence/who_multicountry_study/summary_report/summary_rep ort_English2.pdf . Acesso em: 14 de setembro de 2016.

(2012) World report on violence and health. Genebra: WHO. Acessado em 05/10/2016. Disponível em: http://whqlibdoc.who.int/hq/2002/9241545615.pdf . Acesso em: 14 de setembro de 2016.

\section{Como citar este artigo (Formato ABNT):}

SOUZA, Marjane B.; SILVA, Márcio dos S.; ABREU, Gabriela S de. Violência Doméstica entre Parceiros Íntimos: Questões Culturais e Sociais acerca dos Homens Autores de Violência. Id on Line Revista Multidisciplinar e de Psicologia, 2017, vol.11, n.38, p. 388-407. ISSN: 1981-1179.

Recebido: 30.10 .2017

Aceito: 01.11.2017 